\title{
The Reasons for Joining the English Department
}

\author{
Al-Maqtri Mahmoud Ahmad Thabet ${ }^{1, *}$ \\ ${ }^{1}$ Department of English, College of Sciences and Arts, King Khalid University, P.O.Box:101 \\ Al-namas, Kingdom of Saudi Arabia \\ *Correspondence: Department of English, College of Sciences and Arts, King Khalid \\ University, P.O.Box:101 Al-namas, Kingdom of Saudi Arabia
}

Tel: 966-7-281-0095Ｅ-mail: mmaktri@yahoo.com

Received: September 19, 2012 Accepted: October 21, 2012 Published: December 25, 2012

doi:10.5296/ije.v4i4.2409ＵRL: http://dx.doi.org/10.5296/ije.v4i4.2409

\begin{abstract}
This study is investigating the nature of the reasons of the students for joining the Department of English. The study took place in the College of Sciences and Arts (boys) (affiliated with King Khalid University Al-namas Town, Saudi Arabia). The subjects of the study were 40 level two students (the whole group). The study answered three questions: (1) the frequent reasons they give, (2) comparing them with an equivalent Yemeni sample and (3) finding out if there is some kind of correlation between what the students say and their actual performance in classroom. To collect the data a questionnaire was administered to the group. The results showed that the most frequent reasons were to be translators, to travel abroad to study, to do businesses where English is required, and to find better jobs. Some differences were identified between this group and their Yemeni counterparts. Little correlation was found between the students' statements and their performance in classroom. Some suggestions were offered to teachers to exploit the students' reasons and guide them refine their purposes and do better in accord with what they intend to be.
\end{abstract}

Keywords: reasons; study; English; Saudi; Yemeni; questionnaire; counterparts 


\section{Introduction}

\subsection{The Statement of the Problem}

A considerable number of students join the Department of English to major in English. These students are supposed to have a clear idea and purpose for doing this. Experience shows that many of these students do not have specific purposes for studying English at colleges and universities. Therefore, this study aimed at identifying the nature of the reasons behind joining the Department of English as articulated by the students in the Department of English in the College of Science and Arts in Al-namas (affiliated with King Khalid University, Saudi Arabia).

\subsection{The Rationale for Searching this Topic}

It is an acknowledged fact that to have a clear purpose and specific aim of doing or performing something ensures the positive outcomes and success of that act. In addition, the task for performing such an act becomes easier. This is true of the students of English when they join the Department of English. If they have a clear purpose of the why they choose to major in English and spend four years or more in doing that, they will perform better and their achievement will be higher. Moreover, even when these students have a clear purpose but this purpose is not necessarily associated with using English for a clear, specific and practical task i.e., teaching or traveling, but rather to satisfy another unrelated purpose i.e., to satisfy one's parents' wish or else, this again may not help these students to perform successfully in their study. In many times we encounter students who do not have clear purposes for majoring in English. Oftentimes, they give vague answers to our questions for the reasons behind their majoring in English. The frequent answer they usually give is " because I love it." and "because it is an international language." This study therefore, is intended to find out the reasons why the study group chooses to study English, and to identify the nature of the reasons they give for their choice, and if the reasons they give correlate with their performance in English as reflected in their tests and as observed through their behavior in classroom. Moreover, by addressing this topic, one hopes to draw the students' attention to the fact that they have to have clear purposes for studying English if they want to perform better in their study.

\subsection{The Aims of the Study}

This study aims at the following:

1) To find out the reasons the students give for majoring in English.

2) To compare the reasons the students give with their performance in classroom.

3) To find out if there are any differences with their Yemeni counterparts.

4) To draw the study group's attention to be aware and clear of their purposes behind studying English.

\subsection{Study Questions}

1) What are the most frequent reasons students give for studying English? 
2) Is there correlation between these reasons and the students' performance?

3) Are there any differences between the reasons of this study group and a similar one in Yemen?

\section{Background of the Study}

Learning foreign languages has become an international phenomenon. It is gaining momentum day by day. Learning English language comes at the top of language learning. Certainly, there are reasons for learning English for students all over the world. Some of these reasons are practical, some inspirational, some intellectual and others are sentimental (Omniglot: ND). But whatever one's reasons for learning English in particular are, having a clear purpose of why one learns a language can help to motivate one in his studies.

It has been observed time and again that many students join departments of English with no clear purpose. For these types of students one can imagine how hard the task of learning English can be. Their motivation to learning English can be less as compared to those who have specific reasons for their choice. So students must have a clear purpose in learning English. They must know why they want to learn English. The awareness of the reasons for learning English gives one the right motivation and focus (Resume Template: 2007-2012).

So in order to get benefit from one's course of studying English, he has to identify at least one reason in order to encourage oneself to continue learning English all the time. This can be more mundane a more down -to earth one concerned with daily life of a modest person, to be a teacher of English, or to run a travel agency, for example (Resume Template, 2007-2012 ).

Many reasons for learning languages and for learning English in particular have been identified. First of all, learning English may be the best thing one can do to improve one's life. By learning English one can have access to information and do things that others cannot. Second, if you know English you have better chance to communicate with people around the world where English has become the mode of communication, and where about 1,500,000,000 people in the world speak it and 1,000,000,000 are learning it. (Graddol, 1997). However,

"The importance of English is not just in how many people speak it but in what it is used for. English is the major language of news and information in the world. It is the language of business and government even in some countries where it is a minority language. It is the language of maritime communication and international air traffic control, and it is used even for internal air traffic control in countries where it is not a native language...popular culture--primarily movies and music--carries the English language throughout the world "(Cory).

Third, if a person speaks or knows English he has the privilege of traveling anywhere he/she wants. This is the case because English is spoken in more than 100 countries (CIA World Fact book).

Fourth, people can get a better job if they know English. Many job employers nowadays 
require that a job applicant knows English. Knowing English means getting a good job and earning more money (anitimoon). Some students major in English because they have specific career goals in mind _ most often teaching or writing. Many of these students apply to teachers' education programs after graduation to become elementary or high school teachers (Why Study English).

Many students need to pursue their study abroad and they need English to do that (Why Learn English).

Other students study English in order to sound educated and literate and to advance in the professional world. (Why English Is Important).

The list may not end, but what is important is that students should have a specific purpose in mind when majoring in English which will help them to be successful in their study of English.

\section{The Related Literature}

In the Yemeni Arabic EFL context, Al-Quyadi (2002) carried out a comprehensive study to investigate the psycho-sociological variables in the learning of English in the faculties of Sana'a University in Yemen. One of the main objectives of his study was to examine the nature of the psychological variables of learning English by Yemeni EFL learners in terms of attitudes and motivation as measured by English majors at the Department of English, Faculties of Education at Sana'a University. The only research tool used was a questionnaire. The study sample consisted of 518 students representing seven faculties of Education. Generally, the results showed that the students had a high level of both instrumental and integrative motivation toward the English language. With regard to their attitudes, the findings indicated that the students had positive attitudes towards the English language and the use of English in the Yemeni social and educational contexts.

Still in the Yemeni context, Al-Tamimi and Shuib (2009), carried out a study to identify Petroleum Engineering students' motivation and attitudes towards learning the English language. The study investigated students' motivation in terms of three motivational constructs: instrumental motivation, integrative motivation and personal motivation based on Gardner's (1985) and Cooper's and Fishman's (1977) works. Learners' attitudes, on the other hand, regarding 1) the use of English in the Yemeni social context, 2) the use of English in the Yemeni educational context, 3) the English language and 4) the culture of the English speaking world were identified. The study sample consisted of 81 petroleum engineering students at Hadhramout University of Sciences and Technology (HUST). A questionnaire and interviews were used for data collection. For the students' motivation, the findings showed the subjects' greater support of instrumental reasons for learning the English language including utilitarian and academic reasons. Personal reasons were also regarded as important motives by the students. However, regarding the integrative reasons, the results provided evidence that learning English as a part of the culture of its people had the least impact in students' English language motivation. On the other hand, data for the students' attitudes revealed that most of 
students had positive attitudes towards the social value and educational status of English. In addition, the findings showed the students' positive orientation toward the English language. Interestingly enough, the results indicated that a high number of the students expressed their interest in the culture of the English speaking world as represented by English-language.

As for the Saudi context, a quite recent and relevant study entitled Saudi undergraduate s' motivational orientation towards English Language Learning Along Gender and University Major lines: A Comparative Study (Javid, Al-Asmari \& Farooq, 2012) tried to investigate the Saudi undergraduates' motivational orientations for learning English as a foreign language. It also tried to find out if there exist any significant indicators as regards students' gender and major. The researchers designed a Likert scale questionnaire to collect data. The sample of the study consisted of 709 undergraduate students from three departments among which was English. The results showed that all participants exhibited higher extrinsic motivation with fairly high intrinsic orientations. The result also showed that males of English major revealed more positive attitudes towards both types of motivation as compared to females. As for departments other than English major, more orientation towards extrinsic and intrinsic motivation was shown. In short, the study revealed a significant difference among participants in extrinsic motivation in particular due to difference in gender and major.

With regard to Arab EFL learners, some studies have been undertaken to investigate learners' motivation and attitudes towards the English language. For instance, Qashoa (2006) conducted a study among secondary school students in Dubai. The study aimed at

1) examining the students' instrumental and integrative motivation for learning English, and

2) recognizing the factors affecting learners' motivation. Two research tools were used: a questionnaire and interviews. The sample, for the questionnaire, consisted of 100 students. For the interviews, on the other hand, the sample included 20 students, 10 Arab English teachers and 3 supervisors. The results revealed that students have a higher degree of instrumentality than integrativeness. In addition, the findings indicated that difficulties with the subject (English) aspects such as vocabulary, structures and spelling were found to be the most demotivating factors for the students.

At an international level, a research by the UK Subject Center for languages has identified more than 700 reasons or rationales for learning languages. The research was prompted by the findings of an earlier study of the new landscape for languages (Kelly \& Jones, 2003: p.35), which recommended that rationales for studying languages be collected and classified. The study concludes that the strongest of these reasons are the personal benefits and enjoyment that people gain from learning a language. These findings are significant for a campaign to encourage more people to learn languages in and out of schools. The principal outcome of the study has been the production of an outline database consisting of more than 700 reasons. It is hoped that these reasons for studying languages will facilitate the marketing of languages and will support educators in encouraging secondary schools students to continue with language and to consider doing degrees and in encouraging undergraduates to add a language unit to their degree program. The rationales should also contribute to the design of course program and 
individual units and assist in broadening of overall course aims and objectives.( Kelly, 2004, p.2).

At an international level in an article by Georgiou (2009), the author tried to explore the connection between foreign language education(FLE) and political education. The article criticizes the role of FLE as it adopts facts-oriented approach which is inadequate as it represents the risk of creating and representing stereotypes. For the author, language learners have a need for intercultural skills so that they become tolerant of cultural differences. The author recommends that FLE uses concepts like citizenship education, education for democracy and human rights education to address global citizenship.

An essay by Byram (2002) entitled Foreign language Education as political and moral education discusses the purposes of FL education, and indicates that in the last two or three decades of the twentieth century the purpose for language education has shifted from study of high culture to that of communication. The author advocates the idea that foreign language education should play a role in promoting not only national but also European identity. The White Paper on Learning Society, defines the role of language as linked to three issues: economical proficiency, a sense of belonging identity, and the progress for the individual.

In a book by Crystal (2003) entitled English as a Global Language, the author addresses the issue of English as a global language. He addresses the question of what a global language is and why English is the language that deserved to be in position of a global language. Regarding the why question he addresses the historical context, background, and the legacy of English. In addition, he also discusses the potential dangers of English as a global language. He dedicates the last section of the book to talk about the future of English as a global language.

\section{Methods}

\subsection{The Study Group}

The selected group consists of students of English in their first year of studying English in the College of Science and Arts in Al-namas town, in Saudi Arabia. The sample consists of 40 students (the whole group). All of them are males and their ages range between 19 and 12 .

\subsection{The Delimitation of the Study}

The study sample is limited only to level two (fist year) students of the English Department as this department is in its first year, and they are the first group to join this new Department in the College of Sciences and Arts in Al-namas.

\subsection{Data Collection}

To gather the data from the selected group a questionnaire was used. The implementation of this questionnaire passed through a number of stages. First, the students were asked to list the reasons for joining the Department of English in a piece of paper each. As this was done, the lists were gathered and the items obtained were categorized according their frequency. A long list was drawn that consists of 25 items starting with the most frequent ones. The second 
stage was to give this list again to the students and ask them to choose the reasons that harmonizes with their own purposes. This was done by asking them to put a 'check' next to the reason they chose among the four categories: completely Agree, Agree, Completely Disagree and Disagree. The students were requested to write their names for the purpose of comparing their reasons with their performance.

\subsection{The Validity of the Data Collection Instrument}

As indicated above the construction of the questionnaire passed through different stages. First, the students were asked to brainstorm and list their own reasons for joining the Department of English. The same is not true with Yemeni sample. As this was done, the list was edited and organized according to the most frequent ones. All this ensures the validity of the questionnaire. However, to ensure a more valid version of this questionnaire, the finalized version was given to expert professors and teachers of English. They were requested to check for inconsistency and relevancy of the items and to add other items(reasons). As this was validated the version was finalized and took its final shape. As a result, one more item was added _ the last one as shown in the list, which is related to whether they joined the Department of English for money matters as the Saudis receive monthly stipend by the government while the same is not true of the Yemeni group.

\subsection{The Consistency of the Data Collection Instrument}

To ensure that the questionnaire items are consistent, ten copies were give to a random group of the same main study group. This was one week before it was finally administered to the group. There was consistency between the two events of the questionnaire administering.

\section{The Results and Result Discussion}

\subsection{Results}

The results of the questionnaire are presented in Table 1 below (See attachment 1 for the detailed results). The table represents the questionnaire and the items given. The scores are given in frequency next to each item. The most frequent item is given first.

Table 1: Results of Questionnaire

I joined the English Department because:

1. I want to be a translator.

Frequency

2. English is an international language. 40

3. To communicate with English speaking people. 39

4. I want to travel to an English speaking country. 39

5. The English Department is the best of all departments 38

6. I want to get a good job. 37

7. It is needed in my work.

8. For prestigious purposes. 36

9. I want to be a teacher of English. 36 

2012, Vol. 4, No. 4

10. One day I may need it.

11. I love it.

36

12. I am interested in reading materials in English

13. I got high marks in the secondary school leaving examination.

14. To understand movies, and programs in English.

15. I want to be a caller to Islam.

16. English is required for everyday situations.

17. I want to complete my higher education abroad.

18. I need English for business purposes.

19. To get the monthly pocket allowance

20. My parents wanted me to study English.

21. To use the Internet.

22. I want to be a tourist guide.

23. Other specializations are not available.

07

24. I found my friends joining the English Department.

05

25. I did that just for fun.

\subsection{Result Discussion}

Looking at Table 1 above, we see that there are four categories, but for convenience of analysis the four categories are squeezed into two main categories: the negative two categories into one and the positive two into one.

For convenience of analysis, the list of items is classified into five main groups according to the common features they share. These groups are those that are related to: 1) job, 2) interest and prestige, 3, personal and future uses, 4) family pressure, and 5) others.

1) Those that are related to future job : 3,5,12,13,16,24

2) Those that are related to interest, enjoyment and prestige : 4, 8,9,14,15,21

3) Those related to future personal uses : 2,10,11,18,20

4) Those that are family, peers and friends related 7, 22

5) Others include, 1,6, 17, 19, 23, 25

Those are job related: The first item in this category is item (3) in the main list which states that the purpose for their decision to join the English Department is to be teachers of English in future. A big majority say they want to be teachers of English. Only four out of the total number (40) have a different opinion. For the Yemeni sample, they do not mention that they want to be teacher explicitly. It is only implied in item 5 (see appendix1) that they need it for future job. This is contrary to reality where many English graduates in Yemen work as teachers for the lack of other jobs. Moving to the second item" I want to be a tourist guide" is the fifth item in the list. This time a majority of (26) give a negative response. Only 14 are interested to be tourist guides. The Yemeni counterparts again do not mention this in the open question why did you join the English Department? This happens though other groups of similar students were frequently heard saying they want to be tourist guides. But contrary to 
our expectations they are not interested any more to be tourist guides. This could be attributed to the political and social unrest in Yemen these days. The next item is 12 "to be a translator." This item is one of the very few items in which all participants express a positive attitude towards the statement. All students are interested in becoming translators after graduation. Here there is a big difference with the Yemeni sample, where only two boys said they want to translate books and other materials into Arabic. None of the girls shows interest in this future job. Item 13 comes next in this group: "I need English for business purposes." Twenty three agree with this statement against seventeen; here those who want to use English for business matters are more than those who do not want. For the Yemeni sample this is not in their dictionary of future jobs. This reflects the difference in the economic status of both samples. The Saudis enjoy better living standards and so they are interested in doing business in future. Coming to the last item 24 which states that their intention is to get a job. A big majority are in favor of getting jobs where English is required. Only three students do not agree. For the Yemenis, getting a good job comes number 4 with 10 frequencies out of 28. Here the Saudis are more concerned about future jobs. This is quite strange as the Yemenis are less concerned in getting jobs though they need it more than the Saudis. Is the Saudi sample more thoughtful and more practical?

Those related to interest, prestige and enjoyment: six items come under this group. The first item in this category is number four about their interest in reading material in English. A big majority say they joined the Department of English because they wanted to read material in English. Those who see this as a purpose are 34 out of the total (40). The remaining six say they are not interested. The Yemeni sample does not state this clearly and this is may be because the questionnaire given to them was not refined as the case was with Saudi sample. The next item is (8), the English departments are the best among all departments. This again is one of the frequently heard expressions. Almost all the students either agree or completely agree with this statement. Only two students disagree. Item (9) which states that that they joined the English Department just for fun. None of the students agree. This shows that they are serious. But their actual practicing mismatches completely with reality. The next item in this category is item (14): to understand movies and other programs in English. Only 11 out of 40 do not show this as a purpose. The remaining 29_a majority_ say this is one of the purposes of joining the Department of English. Item (15) comes next. They joined the Department of English because they would feel important. All participants except three are of this opinion. Moving to the last item in this group (21) dealing with the most frequent expression heard by similar groups of students and that is they love English. A majority of 35 out of 40 say they love it. This makes $87.5 \%$ while for the Yemenis it is $11.2 \%$ of the participants. Though "I love it" is an ambiguous statement, yet it is often repeated by students of English. It is not verified what kind of love is this love. It is possible however, that they see the importance of English and its need and use and therefore makes them love it. Or may be their good grade of secondary school has to do something with this love. It is not however a love for the culture as some seem to say when asked to be clear of this love.

Those are related to future personal uses: There are six items under this category. The first one is number two which says that they want to go abroad to complete their study. Almost 
two-thirds of the sample say they want to go abroad. This is justified when we look at the wellbeing status of the Saudi sample. For the Yemeni group only one student expressed his interest of going abroad. This is in agreement with the differences between the two economic status of each group. The Yemenis are less enthusiastic to go abroad because of their impoverished status. The next item is number 10, which states that they learn English to make use of the Internet. Against our expectation those who say they are going to use English for Internet uses are 17 against 23 who have different responses. The second item is 11_using English to communicate with English speaking people. A big majority 39 are of this view. Only one student is against the statement. This is also true of the Yemeni sample. It comes second in importance. Item 18 stating that English is required in everyday situations _ comes next. Two-thirds of the respondents agree with this statement. The last item in this group is item 20 which says that one day they may need it (English). Quite a big majority of 36 think that this is the case. Only four students exhibit a different opinion.

Those that are family or peers related: The first item in this group is item (7) which states that the purpose of their intention to join the Department of English is because their friends joined English so they followed them, one can see that the majority do not agree. Only five out of 40 agree with the statement. The students seem to be very careful in saying they follow their peer fellows blindly. The next item is (22) which states that they joined the department in response to their parents' wishes. The students are almost divided in this point as less than half of the sample disagree. This shows that there are students who joined the department not because they like it but because their parents like it and want them to study English.

Other miscellaneous items . Here the items are not related to one single theme but rather are of a mixed nature. The first of these is the first in the questionnaire list: "because I got high marks in English at secondary school graduation examination." More than two thirds of the participants agree with this statement. Only nine out of 40 disagree. The second item in this category is item (6): to be a caller for Islam. Out of the total 40, a majority of 27 (67.5\%) say they want to be callers for Islam. The remaining 13(32.5\%) say they are not interested in that task and this explains their rationale for studying English. For the Yemeni sample, $11.2 \%$ say they want to be callers for Islam. They study English to serve their religion. This is one of the most frequently heard statements by Arab and Muslim students when asked for their future goal. It is a controversial statement. Are these students sincere in what they say? Our everyday observations negate this for those students who claim to be callers for Islam do not perform their everyday simple Islamic duties like prayer and at least in the college mosques. Further, they do not exhibit true Islamic behavior. For example, they tell lies to their teachers for reasons of being absent or late to classes. Item 17 says that they want to travel abroad where English is in use. The entire group except one agrees with this. For the Yemenis, the same is not true. Only one says he wants to travel abroad. This is in harmony with the reality for the Saudis can afford to travel abroad as tourist, visitors, students and so on. The next item is (19) stating that their decision for joining the Department of English is because there is no other specialization in the college that fits their interest. Here the majority of the students disagree. Only nine agree with the statement. English is an international language is the next item (23) in 
this category. All the students either completely agree or agree with this idea. For their Yemeni counterparts this comes first. Of course, this may mean different things. It could mean they can get jobs where English is required and read material in English and so on. The last item in this group is also the last in the main list of the questionnaire (25). This statement tries to probe if the stipend they receive makes them join the college and thus the Department of English. There is a sharp division among the students in this statement. Exactly, half of the participants agree and the other half disagree that the money they receive from the university is behind their joining the Department of English. This is one of the important statements that tell a lot about the real intention of the students. The students are sincere and they did not try to hide what they believe. It is unusual for many of the students to tell the truth. But this statement belies our stereotyped beliefs about these students. Now this statement is very informing and tells us much why many of these students are not willing to study English as they are too passive inside and outside the classroom. As for the Yemenis, they do not get any such a payment from the government and therefore this does not apply to them.

From the discussion above we can come to answering the study questions as follows:

Question 1: What are the most frequent reasons students give for studying English?

To answer the question we can look back again to Table 1 which shows us the frequencies of each item starting from the most frequent ones moving to the least frequent.

As can be seen, the first reason that all students agree on is to be translators. It comes at the top with $100 \%$ agreement among the students. The second most frequent reason with the same weight is because English is an international language. Though this item does not tell us much as a real reason yet both samples_Saudis and Yemenis_ put it at the top of their choices. The next two frequent items with 39 frequencies are to communicate with English speaking people and to travel abroad to study. English departments are the best is the fifth most frequent reason. Again it does not tell us much as a realistic reason. The next most important item is number six_to get a good job. For the Yemeni sample getting a job comes fourth. If we jump to item 10 "I love it". Here it comes tenth while for the Yemenis it comes sixth. In this the Saudis sample seems to be less enthusiastic to use this empty phrase. "I want to be a caller for Islam" comes number 15 with almost equal weight with their Yemenis counterparts. The last item in the list says that they did not join the department for fun. This shows that they are serious, but their performance negates this.

Question 2: Is there correlation between these reasons as expressed by the students and their performance?

To answer this question Table 2 below shows the correlation for three relevant statements presented in the questionnaire, namely 1, 4 and 21. For brevity and convenience of comparison only five students among those who give positive responses with (Completely Agree) to these statements are selected randomly. The students are given labels as A, B, C, D, E. 
Table 2: Students' Performance against their Verbal Statements

\begin{tabular}{ccccc}
\hline Total (out of 50) & Test2 & Test1 & Students & The statements \\
\hline 12 & 6 & 6 & A. & $1,4,21$ \\
20 & 11 & 9 & B. & \\
48 & 24 & 24 & C. & \\
23 & 13 & 13 & D. & \\
18 & 10 & 8 & E. & \\
\hline
\end{tabular}

We would expect the students actual performance in classroom be representative of what they said regarding their motives for joining the department of English. However, as shown in Table 2 above only student $\mathrm{C}$ got a mark that reflects his expressed statements that he loves English, he likes to read material in English and that he got high marks at school. The mark he got 48 out of 50 is really representative of his opinion about himself. Conversely, the remaining four got marks less than the passing mark (below 25 out of 50). Generally, this means the students are not sincere in what they say about the purpose of joining the English Department. This result is very revealing as it reflects the actual situation in the classroom. Only four out of the total forty students exhibited a real interest in their learning and the student $\mathrm{C}$ is one of them.

Question 3: Are there any differences between the reasons (for joining English department) of this study group and a similar one in Yemen?

The difference between the current Saudi sample and the Yemeni one can be summarized as follows: the Saudi students want to be translators, to travel and to complete their higher study abroad and only then to get jobs. The priority for the Yemenis is to communicate with English speaking people, to know English cultures and traditions and to get better jobs. As can be seen, getting jobs has an equal importance for both samples. We can see the better off status of the Saudis shows itself in their priorities as compared to the Yemenis who want to keep the two ends meet. More Saudis want to travel abroad and, unlike the Yemenis, they are interested to do business and thus make use of English. They are also more interested to be teachers of English. More Saudis want to be callers for Islam. Both samples, however said they loved English. Both appeared to be more emotional than practical; the Saudis and Yemenis said they studied English because it is an international language. Moreover, this emotional aspect could be expressed differently by both groups; the Saudis say that the English Department is the best while they Yemenis say they study English because they want to learn about the English culture and traditions and none of these statements is realistic.

\section{Conclusions}

- The most frequent reasons for joining the Department of English is to be translators, to communicate with English speaking people, to travel abroad to complete further studies and to get a job where English is required. 
- Generally speaking, there is no correlation between what the students say and their actual performance. What they say or dream of does not match with what they are supposed to do in their study: work hard, read materials in English beyond the prescribed course and so on.

- Differences between the current sample and the Yemeni one are reflected in the Saudis' interest to be translators, travel abroad, and start businesses while the Yemenis want to communicate in English and know the target culture.

- Similarities are also found in many items such as finding better jobs, spreading the word of God and so on.

- In both samples, students give some reasons that are not realistic or practical like "English is an international language", "I love English" and so on.

- The Saudi sample statements show that they are more practical and future jobs oriented than their Yemeni counterparts.

- The reasons expressed by the students show that the their motivation is of instrumental nature rather than an integrative one.

\section{Study Limitation}

The study falls short to include more samples from different colleges in both countries. In addition, the Yemeni sample does have the refined list of statements of the questionnaire as the case with the Saudi one.

\section{Suggestions}

1) A more comprehensive survey is required to know the students' reasons behind studying English that includes other groups in different English departments in both countries.

2) It is recommended that teachers know the students' purposes for studying English to help them focus their purposes and interests.

\section{References}

Al-Quyadi, A. (2000). Psycho-sociological variables in the learning of English in Yemen. PhD thesis, Bhagalpur University.

Al-Tamimi, A., \& Munir Shuib (2009). Motivation and attitudes towards learning English: A study of petroleum engineering undergraduates at Hadhramout University of Sciences and Technology .GEMA: Online Journal of Language Studies, 9(2), 29-55.

Antimoon (ND). Why learn English. Retrieved from http://www.antimoon.com/other/whylearn.htm

Byram, M. (2002). Foreign language education as a political and moral education. Language Learning Journal, 26, 43-47. Retrieved from cilt.ittmfl.org.uk/modules/teaching/1g/paper1g3.PDF 


\section{Macrothink}

International Journal of Education

ISSN 1948-5476

2012, Vol. 4, No. 4

CIA World Factbook. (2004-2012). Why learn languages? Retrieved from http://www.vistawide.com/languages/why_languages.htm

Cory, M. Why English is important in our life. Retrieved from http://www.almdares.net/vz/archive/index.php/t-23674.html

Crystal D. (2003). English as a global language(2 ${ }^{\text {nd }}$ edition.). Cambridge University press. http://www.sprachshop.com/sixcms/media.php/811/English_as_a_grobal_lang_sample_ ch.pdf

Georgiou, M. (2009). In Palaiologou N. (ed.). "Intercultural Education: Paideia, Polity, Demoi." Cd-rom Proceedings of the International Conference co-organized by the International Association for Intercultural Education (IAIE) and the Hellenic Migration Policy Institute (IMEPO), under the aegis of UNESCO.

Graddol, D. (1997). The future of English? The British Council.

Javid, C.Z., Al-Asmari, A., \& Farooq, U. (2012). Saudi undergraduates' motivational orientation towards English language learning along gender and university major lines: A comparative study. European Journal of Social Sciences, 27(2), 283-300. http://www.europeanjournalofsocialsciences.com

Kelly M. (2004). In Angela Gallagher-Brett(Seven hundred reasons for studying languages) Retrieved from http://www.llas.ac.uk/resourcedownloads/6063/700_reasons.pdf

Kelly, M., \& Jones, D. (2003). A new landscape for languages. London: The Nuffield Foundation. In Kelly, M.

Omniglot (ND). Why should I learn a language? Retrieved from http://www.omniglot.com/language/why.htm

Qashoa, S. (2006). In Al-Tamimi, A. and Shuib M. (2009) Motivation and attitudes towards learning english: A study of petroleum engineering undergraduates at Hadhramout University of sciences and technology. GEMA: Online Journal of Language Studies, 9(2), 29-55.

Resume Template (2007-2012). Why learn English language. Retrieved from www.learnenglishguide.com

Why English is important: A student essay. Retrieved from http://www.bookrags.com/essay-2004/12/20/17247/09

Why Study English. http://www.english.uottawa.ca/study-english.html 


\section{Appendences}

Appendix A. The Saudi Sample

\begin{tabular}{|c|c|c|c|c|}
\hline I join the English Department because: & C. Agree & Agree & C. Disagree & Disagree \\
\hline $\begin{array}{l}\text { 1. I got high marks in the secondary school leaving } \\
\text { examination. }\end{array}$ & 09 & 22 & 06 & 03 \\
\hline 2. I want to complete my higher education abroad. & 10 & 15 & 03 & 12 \\
\hline 3. I want to be a teacher of English. & 19 & 17 & - & 04 \\
\hline 4. I am interested in reading materials in English. & 08 & 26 & - & 06 \\
\hline 5. I want to be a tourist guide. & 02 & 12 & 09 & 17 \\
\hline 6. I want to be a caller to Islam. & 08 & 19 & 05 & 08 \\
\hline $\begin{array}{l}\text { 7. I found my friends joining the English } \\
\text { Department. }\end{array}$ & 01 & 04 & 24 & 11 \\
\hline $\begin{array}{l}\text { 8. The English Department is the best of all } \\
\text { departments. }\end{array}$ & 20 & 18 & - & 02 \\
\hline 9. I did that just for fun. & - & - & 26 & 14 \\
\hline 10. To use the Intent. & 04 & 13 & 12 & 11 \\
\hline 11. To communicate with English speaking people. & 26 & 13 & - & 01 \\
\hline 12. I want to be a translator. & 18 & 22 & - & - \\
\hline 13. I need English for business purposes. & 05 & 18 & - & 17 \\
\hline 14. To understand films, and programs in English. & 10 & 19 & 01 & 10 \\
\hline 15. For prestigious purposes. & 27 & 10 & - & 03 \\
\hline 16. It is needed in my work. & 25 & 11 & 01 & 03 \\
\hline 17. I want to travel to an English speaking country. & 28 & 11 & - & 10 \\
\hline 18. English is required for everyday situations. & 11 & 15 & - & 14 \\
\hline 19. Other specializations are not available. & 03 & 04 & 19 & 14 \\
\hline 20. One day I may need it. & 23 & 13 & 02 & 02 \\
\hline 21. I love it. & 21 & 14 & 01 & 04 \\
\hline 22. My parents wanted me to study English. & 05 & 13 & 04 & 18 \\
\hline 23. English is an international language. & 31 & 09 & - & - \\
\hline 24. I want to get a good job. & 29 & 08 & 01 & 02 \\
\hline 25. To get the monthly pocket allowance. & 05 & 15 & 14 & 06 \\
\hline
\end{tabular}

Note. C: completely 


\section{Macrothink}

International Journal of Education

ISSN 1948-5476

2012, Vol. 4, No. 4

Appendix B. The Yemeni Sample

\begin{tabular}{|l|l|l|}
\hline Girls & Boys & Item \\
\hline 8 & 9 & Because English is an international language \\
\hline 5 & 9 & To communicate with other speakers of English \\
\hline 5 & 6 & To know their culture, history, customs, tradition \\
\hline 5 & 5 & To find a better job. \\
\hline 3 & 4 & Because English is a window to the world. \\
\hline 2 & 2 & Because I love it \\
\hline 2 & 2 & To spread Islam \\
\hline 3 & 1 & To protect ourselves by learning about how other think and plot \\
\hline 1 & 2 & It is the language of medicine, sports, science and computer \\
\hline-- & 2 & To translate books from English to Arabic. \\
\hline 1 & -- & To express and show others our ideas and beliefs... \\
\hline-- & 1 & To travel abroad \\
\hline
\end{tabular}

Note. (28) boys12 girls 16

\section{Copyright Disclaimer}

Copyright reserved by the author(s).

This article is an open-access article distributed under the terms and conditions of the Creative Commons Attribution license (http://creativecommons.org/licenses/by/3.0/). 